\title{
DIRECTIONS AND TRENDS OF REGIONAL INTELLIGENT SPECIALIZATION IN BULGARIA
}

\author{
P. Atanasova* \\ Department of Regional Development, Faculty of Economics, Trakia University, \\ Stara Zagora, Bulgaria
}

\begin{abstract}
The aim of the report is to draw up the directions for development of the regions in the country, as well as leading trends in intelligent specialization. The starting points are analyzes of the Ministry of Economy and European Business Institute, taking into account the changes in the positions of Bulgaria according to the Global innovation index. Trends in the main innovative activities at NUTS 2 regional level were reported by analyzing objective statistical data of the National Statistical Institute. The changes at the national level in the three production technology groups have also been studied (low-tech, medium-tech, high-tech) as a precondition for regional structural change. Specifying the development trends in the main territorial units in the country will result in a focus on the areas concerned and targeting financial resources to places with the highest potential and perspective.
\end{abstract}

Key words: economic policy, strategy, regions, global innovation index, thematic areas

\section{INTRODUCTION}

Intelligent specialization is an approach to developing the economy through targeted support for research and innovation. This means that it is necessary to develop a strategy for each territory, country or region based on their respective strengths and strengths. The result will be specializing in what can be done best, so as to achieve a distinctive distinction from the other regions, finding its own niche market, through which global competitiveness criteria can be met.

By preparing the Innovation Strategy for Intelligent Specialization in 2013, Bulgaria announces its readiness to change policy and overcome the existing socio-economic challenges in terms of low labor productivity, low share of high-tech production, demographic crisis, and the need to ensure to a higher standard of living for the population.

According to the Global Innovation Scoreboard (1), 2014, in terms of technology readiness (adaptation and application of ICT), Bulgaria ranks 44th in the world (in front of

\footnotetext{
*Correspondence to: Petya Atanasova,

Department of Regional Development, Faculty of

Economics, Trakia University - Stara Zagora,

Bulgaria, phone: 0888897755; e-mail: petya.atanasova@trakia-uni.bg
}

Poland, Romania and Greece). In 2015 - our country ranks 39th in the rankings. In 2016, we are 38th out of 148 countries. 2017 Bulgaria moves two places ahead to 36th innovations in the world.

In its tenth edition, GII 2017 (2) shows the persistent gap in the ability to innovate between developed and developing countries and weak growth in development, both at governmental and corporate level. Bulgaria and Romania are the only two countries in the so-called modest innovators with results far below the EU average. This leads to a widening gap with the next one - that of moderate innovators (including countries such as the Czech Republic, Lithuania and Estonia), said in the European Commission's comparative analysis of innovation, which is being produced annually (3).

The identification of the potential of each economic activity is established by various indicators, which are grouped mainly into two factors - internal (output volume, turnover, added value, labor productivity, employed, number of enterprises and investments in fixed assets) and external factors (export, import and competitive advantages - production and export specialization). The values of all indicators have to be recalculated against 
ATANASOVA P.

overall industry and service estimates to make them comparable and allow their aggregation and internal and external valuation estimates. As a result, the sum of these two factors gives the final estimate for each economic activity.

The role of the internationalization of the innovation process in Bulgaria and the integration of Bulgarian research and innovation into the European Union's Entrepreneurship Program is of paramount importance. This is a difficult and lengthy process, but it leads to sustainable competitiveness of the country. Investing in innovation activity in specific technology areas would reduce the resources used, increase productivity, achieve stable production quality, implement and develop software and engineering activities, attract foreign investment to leading international companies, and hence strengthen the cooperation and internationalization of the industry.

Innovation that is based on research is an important factor in public progress and the growth of the economy. A major factor driving the boundaries of technological development is science. Fundamental scientific discoveries have led to the development of mankind, creating new technological platforms, such as the genetic revolution and the further development of biotechnology that has led to improvements in health and agriculture (4).

By applying new knowledge, new products, technologies and business models can be generated. Knowledge generated by research institutes is disseminated through various channels - academic mobility, scientific publications, conferences, research on industry agreements and patenting of university discoveries and inventions (5).

Research is becoming increasingly multidisciplinary on a global level. Some areas, such as mathematics, are so intertwined in the research system that they do not have a separate label (6). As a consequence, innovation usually occurs at the border or in the crossing area of the different disciplines.

ISIS recommends that Bulgaria focus on industrial and technological modernization, which complements the focus on growth-based research (7). This modernization is based on the inclusion of foreign partners and therefore can not be a stand-alone process. Increasing productivity in Bulgaria in the medium term is possible through innovative resource-efficient and ICT-enabled solutions for the country, while modernization is achieved through improvements in production potential and on the basis of new equipment and raw materials and not just research.

\section{TRENDS IN THE THEMATIC AREAS OF THE INTELLIGENT SPECIALIZATION AND INNOVATION SYSTEM IN BULGARIA}

On the basis of analyzes, studies and meetings conducted by the Ministry of Economy and the Bulgarian Academy of Sciences, thematic areas have been developed, which have potential for development in accordance with the characteristics and indicators of the planning regions or the so- statistical areas NUTS 2. There are four thematic areas in ISIS where Bulgaria has a competitive advantage at the present moment.

The first thematic area is: "Informatics and Information and Communication Technologies". It includes computer and communication equipment, electronic and optical products, telecommunications services, information technology services, research. In recent years, ICT activities in Bulgaria have been mainly oriented towards the development of software and information systems. Bulgaria is still one of the main ICT outsourcing destinations. (Hewlett Packard, IBM, VMware, SAP Net Weaver, Software AG Development Center Bulgaria, Johnson Control Technology Center Sofia). Other ICT leaders performing in Bulgaria development and services are Microsoft, Cisco, EMC, Xerox, Ericsson (8). Table 1 presents Bulgaria in this area in the international charts.

The second thematic area is: "Mechatronics and Clean Technology". Its subdivisions in the Mechatronics section are mechanics, electronics, software and management systems, but in pure technologies - eco-mobility, including eco-mobility, electric vehicles and storage and energy saving. Mechatronics was registered as a trademark by "Yaskawa Electric Corporation" in Japan with the registration number of "46-32714" in 1971. From countries in the European Union, there is a French standard NF E 01-010 for mechatronics. In our country, mechatronics has strong positions in line with the world trends in the development of the most promising and innovative areas of engineering, combining the experience and traditions of a particular European or international interest. This allows Bulgaria to engage directly in global value chains. 
Mechatronics is a mutual merger of mechanical, electronic and computer structures for the realization of a complete, functionally complete product, called "mechatronic product" or "mechatronic product". It should be noted that Bulgaria has a certain capacity in terms of robotics, artificial intelligence and intelligent devices and modern production systems.

Table 1. Bulgaria's ICT sector in international charts

\begin{tabular}{|l|l|l|l|}
\hline Global Innovation Index & \multicolumn{2}{l|}{$\begin{array}{l}\text { Position in the } \\
\text { world }\end{array}$} \\
\hline code & Indicator & $\mathbf{2 0 1 4}$ & $\mathbf{2 0 1 6 - 2 0 1 7}$ \\
\hline $\mathbf{3 . 1}$ & Information and Communication Technologies & $\mathbf{6 7}$ & $\mathbf{5 5}$ \\
\hline 3.1.1 & Access to ICT & 47 & 50 \\
\hline 3.1.2 & Application of ICT & 43 & 44 \\
\hline 5.3.3 & Import of ICT and services & 67 & 65 \\
\hline 6.2.3 & Software costs & 40 & 43 \\
\hline 6.3.3 & Export of ICT and services & 40 & 41 \\
\hline 7.1.3 & ICT and business models & 101 & 72 \\
\hline 7.1.4 & ICT and the creation of organizational models & 99 & 62 \\
\hline Global Competitiveness Index (148 countries) & & \\
\hline 9 & Technological readiness (adaptation and application of ICT) & 44 & 38 \\
\hline
\end{tabular}

Source: Innovation and Entrepreneurship Division, Economic Promotion Policies Directorate, Ministry of Economy, 2017

A third thematic area is highlighted: "Industry for Healthy Life and Biotechnology". The innovative strategy for intelligent specialization encourages the following priority directions: methods of clean production, storage, processing and reaching the end user of specific Bulgarian ingredients, means and products (including yoghurt, honey and bee products, bread, wine, dairy and meat products, essential oils, beer, herbs and herbal products, cosmetics and products), production of specialized foods and beverages (baby and children's, "space" foods), production of tools, equipment, personal medicine, diagnostics and individual therapy, medical and pharmaceutical forms and means.

The fourth thematic area is "New Technologies in Creative and Recreational Industries". By definition, the creative industries in Bulgaria include the following groups of activities: publishing, software, music, visual and performing arts, television, radio, films, video and photography, computer games, advertising, architecture, design, crafts (9).

\section{REGIONAL SPECIALIZATION IN LEADING INNOVATION ACTIVITIES} Innovation and Entrepreneurship Division, Directorate "Investments, Innovation and Entrepreneurship" at the Ministry of Economy prepares a regional specialization of leading innovative activities on BVD Amadeus company information database. 216 economic activities, the third level of aggregation of all business activities (NACE 2008), excluding financial services and agrarian production, are covered. All business activities are tied to a coefficient (innovation score) and ranked in descending order. Economic activities are analyzed - 25 leading business activities on innovation. As a criterion for regional potential, employment is assumed to be at least $10 \%$ of those employed in the relevant business activity in a planning region (Table 2)

In Table $\mathbf{2}$ is visible a strong focus on leading innovation activities in the Southwest region (SWR), mainly in Sofia. By reducing the innovation assessment of the activities there is a "export" of the specialization outside Sofia to South Central and Eastern Bulgaria. The production of medicinal products is concentrated in Pazardzhik and Kyustendil, production of computer equipment in Blagoevgrad, Veliko Tarnovo and Plovdiv, optical devices and photographic equipment in Panagyurishte, activities of news agencies in Plovdiv and Varna. In order to improve human resources, it is necessary to establish a link between the demands of the business and the labor market and higher education by increasing practical training. The recruitment 
ATANASOVA $P$.

of highly qualified staff, practices and specializations with students and pupils and the recruitment of young specialists should be encouraged. The legislative environment needs to be improved and aimed at supporting startups with graduate students, the deployment of new technologies in small and medium-sized enterprises. For the purpose of recruiting young highly qualified specialists and $\mathrm{PhD}$ students, companies in the relevant fields can be subsidized. This will increase the innovativeness of small and medium-sized businesses without available human and financial resources for research and development.

Table 2. Summary results for the leading innovation activities (specialization by statistical regions,

$\%$ of total employment)

\begin{tabular}{|c|c|c|c|c|c|c|c|c|}
\hline & economic activity & \begin{tabular}{|l|} 
employ \\
ment \\
\end{tabular} & NWR & NCR & NER & SWR & SCR & SER \\
\hline 1 & R \& D in the field of medical, natural and technical sciences & 8998 & 6.2 & 2.0 & 4.1 & 76.0 & 5.9 & 5.8 \\
\hline 2 & Publishing of software products & 925 & 0.0 & 1.5 & 2.4 & 89.7 & 5.5 & 0.9 \\
\hline 3 & R \& D in the social and human sciences & 1861 & 0.1 & 0.1 & 0.0 & 94.0 & 5.9 & 0.1 \\
\hline 4 & Satellite telecommunication activity & 1528 & 0.5 & 0.3 & 0.8 & 98.4 & 0.0 & 0.0 \\
\hline 5 & Manufacture of medicinal products & 7327 & 8.0 & 5.5 & 1.3 & 57.0 & 23.2 & 5.0 \\
\hline 6 & Activities in the field of information technology & 26134 & 0.8 & 3.1 & 5.1 & 82.7 & 4.8 & 3.4 \\
\hline 7 & Wireless telecommunication activity by wireless means & 7621 & 0.2 & 0.1 & 0.5 & 98.2 & 0.5 & 0.5 \\
\hline 8 & Other information services - news agencies & 2134 & 2.2 & 1.9 & 21.0 & 65.9 & 6.7 & 2.3 \\
\hline 9 & Creating and broadcasting radio programs & 2196 & 0.7 & 1.0 & 2.1 & 90.6 & 3.6 & 2.0 \\
\hline 10 & Creation and broadcasting of television programs & 4507 & 1.8 & 2.7 & 2.0 & 81.6 & 6.8 & 5.1 \\
\hline 11 & Production of pesticides & 244 & 8.6 & 2.0 & 7.0 & 4.5 & 77.9 & 0.0 \\
\hline 12 & Production of radio, TV and telecommunication equipment & 1136 & 3.6 & 9.3 & 4.0 & 61.1 & 20.7 & 1.2 \\
\hline 13 & Manuf acture of computer equipment & 398 & 0.3 & 20.1 & 3.0 & 67.8 & 8.8 & 0.0 \\
\hline 14 & Manuf acture of instruments for measuring, navigating, clocks & 2442 & 5.8 & 2.9 & 16.1 & 48.4 & 21.9 & 5.0 \\
\hline 15 & Architectural and engineering activities & 21050 & 3.7 & 5.4 & 9.9 & 61.5 & 10.7 & 8.8 \\
\hline 16 & Manufacture of electromedical apparatus & 141 & 1.2 & 4.3 & 11.9 & 73.0 & 5.6 & 4.1 \\
\hline 17 & Management consulting services & 9162 & 1.2 & 4.3 & 11.9 & 73.0 & 5.6 & 4.1 \\
\hline 18 & Activities of central offices & 598 & 1.7 & 2.7 & 38.8 & 53.3 & 1.0 & 2.5 \\
\hline 19 & Manufacture of consumer electronics & 322 & 0.0 & 0.9 & 7.1 & 84.5 & 7.5 & 0.0 \\
\hline 20 & Manufacture of optical instruments and photographicequipm & 1104 & 0.0 & 0.0 & 0.4 & 31.0 & 68.3 & 0.4 \\
\hline 21 & Wholesale of computers and communication equipment & 5801 & 1.9 & 2.2 & 5.4 & 79.2 & 8.2 & 3.0 \\
\hline 22 & Other telecommunication activities - Internet access & 1824 & 2.4 & 6.1 & 4.9 & 70.1 & 7.8 & 8.7 \\
\hline 23 & Specialized design activities & 968 & 3.4 & 3.0 & 21.0 & 54.1 & 11.8 & 6.7 \\
\hline 24 & Activities in the field of photography & 1590 & 6.9 & 9.5 & 17.8 & 39.8 & 12.6 & 13.4 \\
\hline 25 & Production of basic chemicals & 4114 & 1.1 & 3.9 & 38.0 & 12.9 & 36.7 & 7.4 \\
\hline
\end{tabular}

Source: Ministry of Economy, Department "Imovation and Entrepreneurship", 2013

Table 3 shows an increased number of people employed in the field of Research and Development. Again, the Southwestern region is the highest employment, followed by the
South Central and the Northeast. The lowest number of people employed in this area is Northwest, with the lowest growth for the period - South-East.

Table 3. Staff engaged in $R \&$ D by statistical regions for period $2009-2017$

\begin{tabular}{|c|c|c|c|c|}
\hline \multirow[t]{2}{*}{ Statistical Regions } & \multicolumn{2}{|c|}{$\begin{array}{c}\text { employed (number of } \\
\text { persons) }\end{array}$} & \multicolumn{2}{|c|}{ growth rate } \\
\hline & 2009г. & 2017г. & absolute & $\%$ \\
\hline Total for the country & 21971 & 31221 & 9250 & 42.10 \\
\hline Northwest & 624 & 1396 & 772 & 123.72 \\
\hline North Central & 1565 & 2120 & 555 & 35.46 \\
\hline Northeast & 2032 & 3388 & 1356 & 66.73 \\
\hline Southeast & 1732 & 2119 & 387 & 22.34 \\
\hline Southwest & 14129 & 18837 & 4708 & 33.32 \\
\hline South Central & 1889 & 3361 & 1472 & 77.92 \\
\hline
\end{tabular}

Own calculations according to NSI data 
Table 4 presents employment data in the field of "Creation and dissemination of information and creative products, telecommunications" in 2009 and 2016 and shows that in this area of economic activities by 2016, there is an increase in the number of people employed mainly in the Southwest region, while in the rest there is a decrease in the number of people involved. The indicated growth of 22,488 individuals in the Southwest Region Table represents a significant increase in this type of activity over the monitored period.

Table 4. Staff employed in the field of "Creation and dissemination of information and creative products, telecommunications" by statistical regions 2009 - 2016

\begin{tabular}{|c|r|r|r|r|}
\hline \multirow{2}{*}{ Statistical Regions } & \multicolumn{2}{|c|}{$\begin{array}{c}\text { employed (number of persons in } \\
\text { thousand) }\end{array}$} & \multicolumn{2}{c|}{ growth rate } \\
\cline { 2 - 5 } & $\mathbf{2 0 0 9 \Gamma}$ & $\mathbf{2 0 1 6}$. & absolute & \% \\
\cline { 2 - 5 } & 68.457 & 90.195 & 21.738 & 31.75 \\
\hline Total for the country & 1.854 & 1.306 & -0.548 & -29.56 \\
\hline Northwest & 2.454 & 2.218 & -0.236 & -9.62 \\
\hline North Central & 4.781 & 4.507 & -0.274 & -5.73 \\
\hline Northeast & 2.906 & 2.537 & -0.369 & -12.70 \\
\hline Southeast & 52.257 & 74.745 & 22.488 & 43.03 \\
\hline Southwest & 4.205 & 4.882 & 0.677 & 16.10 \\
\hline South Central & & & &
\end{tabular}

Own calculations according to NSI data

Table 5 shows us increased internet access for households over the period (over 9 years more than 2 times). It shows the development of the society and the increase of the skills in the Internet space. This is a prerequisite for increased use of public electronics applications for information, e-banking, service requests and other expanded opportunities, reducing administrative costs for servicing citizens.

Table 5. Household Internet Access by Statistical Regions for 2009-2018

\begin{tabular}{|c|c|c|c|}
\hline \multirow{2}{*}{ Statistical Regions } & 2009 & 2018 & growth rate \\
\hline & \multicolumn{3}{|c|}{ percentage points } \\
\hline Total for the country & 29.6 & 72.1 & 42.50 \\
\hline Northwest & 24.7 & 65.2 & 40.50 \\
\hline North Central & 23.6 & 68.5 & 44.90 \\
\hline Northeast & 26.8 & 73.9 & 47.10 \\
\hline Southeast & 26.8 & 70.0 & 43.20 \\
\hline Southwest & 40.3 & 75.3 & 35.00 \\
\hline South Central & 25.6 & 73.7 & 48.10 \\
\hline
\end{tabular}

$*^{-}$The relative share is calculated on the basis of a population of 16 to 74 years.

Own calculations according to NSI data

The following Tables 6, 7, 8 represent the specialization of low-tech, medium-tech and high-tech industries in our country. Own calculations were made, according to data from the National Institute of Statistics - Infostat in 2018 to track and analyze developments in the relevant industries.

The low-tech manufacturing group (Table 6) covers economic activities in the food and textile industries. High degree of specialization is observed in the "Clothing", "Food", "Textiles" and "Leather and Shoes" sector.

By 2018 the largest number of staff employed in the "Food Production" and "Production of Clothing" activities were registered, with a decrease in the number of employees compared to 2009. Of the other productions examined, a high share is "Furniture production", but also the number of staff employed in 2018 is lower than in 2009. All other economic activities have a similar number of staff employed between 8500 and 
11700 people. The smallest share is attributed to "Manufacture of tobacco products". It should be noted that over the period of 10 years, all the above-mentioned industries have a lower number of engaged staff. According to
NSI data, it can be summarized that recruited personnel in 2018 is about 82,000 people less than in 2009. This is probably due to the demographic crisis facing our country in recent years.

Table 6. Staff employed in low-tech economic activities

\begin{tabular}{|l|l|r|r|r|r|}
\hline \multicolumn{1}{|c|}{ Economic activities } & \multicolumn{1}{c|}{$\begin{array}{c}\text { Eurostat } \\
\text { code }\end{array}$} & \multicolumn{2}{c|}{$\mathbf{2 0 0 9}$} & \multicolumn{2}{c|}{$\mathbf{2 0 1 8}$} \\
\cline { 4 - 6 } & employed & share\% & employed & share\% \\
\hline Manufacture of food products & $\mathrm{C} 10$ & 85384 & 7.72 & 73593 & 7.19 \\
\hline Manufacture of beverages & $\mathrm{C} 11$ & 15144 & 1.37 & 11633 & 1.14 \\
\hline Manufacture of tobacco products & $\mathrm{C} 12$ & 3764 & 0.34 & 1364 & 0.13 \\
\hline $\begin{array}{l}\text { Manufacture of textiles and textile products, } \\
\text { except apparel }\end{array}$ & $\mathrm{C} 13$ & 12203 & 1.10 & 11605 & 1.13 \\
\hline Manufacture of clothing & $\mathrm{C} 14$ & 108257 & 9.79 & 78118 & 7.63 \\
\hline $\begin{array}{l}\text { Leather processing; Manufacture of articles made } \\
\text { from processed hides and skins }\end{array}$ & $\mathrm{C} 15$ & 19290 & 1.74 & 11509 & 1.12 \\
\hline $\begin{array}{l}\text { Manufacture of wood and of products of wood, } \\
\text { except furniture }\end{array}$ & $\mathrm{C} 16$ & 14370 & 1.30 & 13909 & 1.36 \\
\hline $\begin{array}{l}\text { Manufacture of paper, paperboard and other } \\
\text { products of paper and paperboard }\end{array}$ & $\mathrm{C} 17$ & 9124 & 0.83 & 9279 & 0.91 \\
\hline Printing and reproduction of recorded media & $\mathrm{C} 18$ & 9424 & 0.85 & 8577 & 0.84 \\
\hline Furniture manufacturing & $\mathrm{C} 31$ & 23298 & 2.11 & 19260 & 1.88 \\
\hline
\end{tabular}

Own calculations according to NSI data

Table 7. Staff in economic activities with medium-tech productions

\begin{tabular}{|l|l|l|l|l|l|}
\hline Economic activities & \multirow{2}{*}{$\begin{array}{l}\text { Eurostat } \\
\text { code }\end{array}$} & $\mathbf{2 0 0 9}$ & $\mathbf{2 0 1 8}$ \\
\cline { 3 - 6 } & employed & share\% & employed & share\% \\
\hline Manufacture of rubber and plastic products & $\mathrm{C} 22$ & 24141 & 2.18 & 29635 & 2.90 \\
\hline $\begin{array}{l}\text { Manufacture of other non - metallic } \\
\text { mineral products }\end{array}$ & $\mathrm{C} 23$ & 25264 & 2.28 & 20394 & 1.99 \\
\hline Manufacture of basic metals & & & & 1.26 \\
\hline $\begin{array}{l}\text { Manufacture of fabricated metal products, } \\
\text { except machinery and equipment }\end{array}$ & $\mathrm{C} 24$ & 13733 & 1.24 & 12855 & 1.45 \\
\hline Manufacture of electrical equipment & $\mathrm{C} 27$ & 18609 & 1.68 & 27358 & 2.67 \\
\hline $\begin{array}{l}\text { Manufacture of machinery and equipment, } \\
\text { general and special }\end{array}$ & $\mathrm{C} 28$ & 26976 & 2.44 & 31534 & 3.08 \\
\hline $\begin{array}{l}\text { Manufacture of motor vehicles, trailers and } \\
\text { semi - trailers }\end{array}$ & $\mathrm{C} 29$ & 11005 & 1.00 & 24047 & 2.35 \\
\hline $\begin{array}{l}\text { Manufacture of motor vehicles, not motor } \\
\text { vehicles }\end{array}$ & $\mathrm{C} 30$ & 5465 & 0.49 & 5059 & 0.49 \\
\hline $\begin{array}{l}\text { Repair and installation of machinery and } \\
\text { equipment }\end{array}$ & $\mathrm{C} 33$ & 14624 & 1.32 & 14545 & 1.42 \\
\hline
\end{tabular}

Own calculations according to NSI data

Table 8. Staff employed in economic activities with high-tech productions

\begin{tabular}{|c|c|c|c|c|c|}
\hline \multirow{2}{*}{ Economic activities } & \multirow{2}{*}{$\begin{array}{c}\text { Eurostat } \\
\text { code }\end{array}$} & \multicolumn{2}{|c|}{2009} & \multicolumn{2}{|c|}{2018} \\
\hline & & \begin{tabular}{|l} 
employed \\
\end{tabular} & share\% & employed & share\% \\
\hline $\begin{array}{l}\text { Manufacture of computer equipment, electronic } \\
\text { and optical products }\end{array}$ & $\mathrm{C} 26$ & 7581 & 0.69 & 10530 & 1.03 \\
\hline $\begin{array}{l}\text { Production of films and TV shows, sound } \\
\text { recording and music publishing }\end{array}$ & J59 & 2191 & 0.20 & 1955 & 0.19 \\
\hline Radio and television activities & J60 & 3624 & 0.33 & 2365 & 0.23 \\
\hline Telecommunications & J61 & 20170 & 1.82 & 18924 & 1.85 \\
\hline Activities in the field of information technology & J62 & 21212 & 1.92 & 47163 & 4.61 \\
\hline Information services & J63 & 4558 & 0.41 & 11243 & 1.10 \\
\hline
\end{tabular}

Own calculations according to NSI data 
The following group of economic activities is considered to be those of medium and medium-sized technological productions Table 7. It includes economic activities: "Rubber, plastics", "Non-metallic mineral raw materials", "Basic metals", "Metal products", " Machinery and equipment ", " Vehicles ", "Vehicles "and "Repair and installation of machinery and equipment ".

In this group the activities with the highest share are "Manufacture of metal products, except machinery and equipment" - 5,4\% of the engaged staff for 2018. There is an increase compared to 2009. This highlights the growth of this type of production over the 10-year period observed. Other activities in which there is an increase in the number of engaged staff are: "Manufacture of rubber and plastic products" (with 5494), "Manufacture of electrical equipment" (with 8749), "Manufacture of machinery and equipment, general and special purpose" (with 4558) and" Manufacture of motor vehicles, trailers and semi-trailers "(by 13042).

In the group of high-tech production and hightech and intensive knowledge and services are included economic activities: "Production of computer and communication equipment, electronic and optical products", "Production of films and TV programs, sound recording and music publishing", "Radio and television activities", "Telecommunications", "Information technology activities" and "Information services" - Table 8. According to NSI data and the Amadeus database, the hightech industrial sectors account for $6.1 \%$ of the total exports, giving them the third place of export per employee after the export of petroleum products and basic metals.

The data in Table 8 shows an increase in employment in the field of information technology, information services and computer equipment production. Over the 10-year period, we have about twice as many staff involved in this group of activities. This proves the potential of our country in the information technology and services sector.

\section{CONCLUSIONS}

The development of software and information systems in our country identifies Bulgaria as one of the main ICT outsourcing destinations in recent years. Leaders such as Microsoft, Cisco, EMC, Xerox, Ericsson are engaged in development and services. Mechatronics also has strong positions in our country in line with the world trends in the development of the most promising and innovative fields of engineering sciences, bringing together the experience and traditions of European or international interest.

Depending on the different natural circumstances, there is a potential in the production of specialized foods as well as in the development of biotechnology. Bulgaria is one of the richest countries of mineral waters in Europe and this is a strong prerequisite for the development of medical, healing and recreational tourism. Given the varied nature, we also have conditions for alternative (cultural, rural, festival) and extreme tourism and sports.

In recent years, staff employed in $\mathrm{R} \& \mathrm{D}$ have increased by $42 \%$. The largest is the number of employed in the Southwest region (more than half of the absolute rate of growth).

With respect to those employed in the area of "Information and Creativity and Telecommunication", the country level increase is $31 \%$, with the real increase in the Southwest region, almost all others have staff cuts without South Central there is an increase of 677 people).

With regard to household access to the Internet, there has been an increase of 42.5 percentage points over the last 10 years in the general sample of the population aged 16 to 74.

In the low-tech industries at the end of 2018, the largest share of employees in the food and clothing sector, these shares being reduced compared to 2009. For medium-tech: with the highest share in 2018 is the manufacture of metal products, of machinery and equipment, of rubber and plastic products and of electrical equipment. These areas are characterized by an increase in staff compared to 2009. In the case of high-tech manufacturing, the greatest number of employees is in the field of information technology. The increase over the 10 -year period is more than doubled.

Overall, about 82,000 jobs have decreased in our country between 2009 and 2018. Probable reason for this is the demographic crisis and the migration of young people, the demand for better opportunities for realization in other countries.

The recommendations that may be made are in several ways: 
Develop measures to increase the number of qualified human resources in the country and regions. This is primarily related to the retention of qualified young specialists after their graduation in Bulgaria, assisting the business in recruiting young professionals.

State support for business in initiating and implementing innovative solutions in the relevant sectors. Demonstrating the economic sense of certain models in production stimulates their introduction and popularization. Demonstration initiatives are practices in many countries and this brings the resource-efficient technology closer to society and business.

Providing investment and consultancy support would support the implementation of enterprise innovation and technology transfer. It is crucial to build business-academia-tobusiness partnerships, including cluster creation and networking and platforms. Special schools for the training of cluster staff can be set up and new developments in the relevant areas can be studied in parallel.

Orientation of research into business problems and practice as a whole. This would generate revenue for research institutions and increase the market potential of $\mathrm{PhD}$ students involved in this type of research. The dissemination of knowledge and research is done through a variety of channels - mobility, scientific publications, international conferences, industry studies and licensing of innovation. This is crucial for applications in the economy. A wider internationalization of sciencebusiness interconnections is needed to foster innovation progress and the competitiveness of countries and regions. A serious prerequisite for this is the participation of Bulgaria in various organizations such as CERN, ESA, initiatives for BBI (biologically based industries), which will lead to faster knowledge transfer and innovation, and will retain quality scholars.

The high level of research at higher education institutions must be stimulated and provoked because they have a leading role in technological and innovation progress. Knowing the trends and development potential in the country's territorial units will result in focusing on the respective areas and identifying the places with the highest potential and the prospect of intelligent specialization.

\section{REFERENCES}

1. The Cornell University Global Innovation Index, the European Institute of Business Administration INSEAD and the United Nations Copyright Agency (WIPO) https://www.globalinnovationindex.org/Ho me

2. The Global Innovation Index 2017, https://www.globalinnovationindex.org/gii2017-report

3. Capital, Bulgaria remains the penultimate innovator in the EU, 21 June 2017, 17:14

4. National Strategy for Research Development 2020, Scientific Research Fund, Ministry of Education and Science, 2014

5. Innovation.bg, Applied Research and Communications Foundation, 2013

6. Raffles, Porter, Leydersdorf, Maps with overlapping scientific disciplines: new a tool for defining strategies in the research field, 2009

7. Innovative Strategy for Intelligent Specialization of the Republic of Bulgaria 2014-2020

8. Analyzes of the Bulgarian Industrial Association, $2014 \quad$ - http://www.biabg.com/analysis/

9. National Strategy for the Development of the Creative Industries in Bulgaria, 2014 https://bsc.smebg.net/redi/resources/Nation al.pdf 